\title{
Processing Factors, Academic Discourses, and Local and Global Comprehension
}

\author{
STEPHEN B. KUCER \\ Washington State University
}

\begin{abstract}
The relationship among a variety of processing factors and the comprehension of literary and scientific academic discourses of fourth grade readers was examined. In general, a different matrix of processing behaviors were associated with recall within the two disciplinary discourses at both the clause and main idea. For the literary text, clauses that maintained author meaning with or without miscues were significantly more likely to be recalled. However, processing that changed the meaning of the clause, although still meaningful in and of itself, was less likely to be recalled. For the scientific text, processing behaviors were not found to be as directly related to comprehension, with one exception. Clauses containing miscues that maintained author meaning were significantly more likely to be recalled than clauses with no miscues. In terms of similarities, clauses read in a manner than maintained the author's meaning, regardless of the existence of miscues, were positively correlated with local and global levels of comprehension on both discourse types. Additionally, the recall of ideas on the clause level was also predictive of the recall of major ideas for the scientific and literary texts. Interestingly, words read per minute, accuracy, reading levels as determined by the Qualitative Reading Inventory, and oral reading fluency as determined by DIBELS were unrelated to strong retellings.
\end{abstract}

\section{Processing Factors and Text Comprehension}

The current focus on the role of fluency on reading development and proficiency has led to renewed attention on how written discourse is processed. The common, as well as contested, use of the Dynamic Indicators of Basic Early Literacy Skills (DIBELS; Good \& Kaminski, 2005) in many elementary classrooms to measure fluency has only intensified the interest. Paralleling this focus on fluency has been a concentration on the very nature of academic discourses, especially expositions, and their impact on reader comprehension. Academic discourses reflect the specialized ways with language, ideas, and thinking related to such disciplines as history and mathematics. This is in contrast to vernacular discourses, which reflect the language and experiences of the home and community.

The notion that various disciplinary texts make varying linguistic, cognitive, and sociocultural demands on readers has become a well-established belief within the literacy community. Not surprisingly, much of the discussion around academic literacy has been on expository discourse, scientific in particular (e.g., Cavagnetto, 2010; Fang, 2004; Gee, 2004; Honig, 2010; Shanahan, 2004a, 2004b, 2009). Such a focus parallels the national and international focus on science, technology, engineering, and mathematics (STEM). 
Interestingly, with some exceptions (e.g., Kucer, 2011; Walczyk \& Griffith-Ross, 2007), most of the fluency research has involved the use of literary narrative texts (e.g., Dowhower, 1994; Rasinski, 2006; Stahl \& Heubach, 2005). However, at least outside of classroom settings, expositions are encountered on a daily basis by most readers. Additionally, there is lack of research that has closely examined-and compared and contrasted - the actual processing behaviors and comprehending patterns of students reading across the disciplines. Much of the discussion of academic language has tended to be of a discourse analysis nature (i.e., an examination of the internal workings of the text), unaccompanied by real readers reading and comprehending

This study builds upon the current interests in fluency and academic literacy by bringing them together and extending the existing research. First, it examines the relationship among various processing factors-including but not limited to fluencyand comprehension. Secondly, this processing-comprehension relationship is examined through the use of two disciplinary texts. Specifically, the following questions were explored:

1. What is the relationship among various processing behaviors and comprehension within a literary narrative and scientific expository text?

2. What is the relationship among various processing behaviors and comprehension between a literary narrative and scientific expository text?

\section{Theoretical and Research Framework}

As one of the five pillars of reading and reading instruction identified by the National Reading Panel (NICHD, 2000), fluency has become a topic of intense interest, both in the elementary classroom and in the research community. This is the case even though the very nature of the construct is contested (Breznitz, 2006). Fluency, a product of automaticity, is viewed as a prerequisite to comprehension because it frees cognitive resources for the construction of meaning. Readers need not focus attention on word identification. Instead, they can use their energies and capacities to build an understanding of the text. Originally defined by Samuels (1979) as consisting of accuracy and speed, others have added the dimension of prosody-expression, stress, tempo, rhythm - to the fluency definition (Rasinski, 2006). Even here, there is some debate within the literacy community as to whether fluency is a prerequisite to comprehension or if it is comprehension itself that allows the reader to be fluent (Kuhn \& Stahl, 2004; Rasinski, Reutzel, Chard, \& Linan-Thompson, 2011). Similarly, there is dispute over whether prosody is a separate dimension within fluency. Or, is prosody captured within speed and accuracy? Or, does prosody simply reflect the fact that comprehension has occurred (Hudson, Pullen, Lane, \& Torgesen, 2009; Torgesen \& Hudson, 2006)? Finally, rubrics have frequently been used to measure prosody, which may limit "the precision of the assessment and the potential for capturing the robustnesses of potential relationships" (Rasinski, et al., 2011, p. 293-294).

Paris, Carpenter, Paris, \& Hamilton (2005) have noted that high levels of fluency and accuracy are "neither necessary nor sufficient for comprehension" (p. 141) to occur. Nor is speed necessarily positively correlated with comprehension. For example, it is well documented that there are children who are proficient at decoding and speed, yet still fail to comprehend (e.g., Allington \& McGill-Franzen, 2009; Paris \& Hamilton, 2009). There 
is most likely a minimal threshold at which these constrained processing factors are necessary. Higher-level processes can only be performed when thresholds for such factors as speed and accuracy are reached. However, determining threshold values "is difficult because it varies according to context, familiarity, and all the other skills involved in language comprehension" (Paris \& Hamilton, 2009, p. 32). As readers progress developmentally, the role of these constrained skills diminish and other unconstrained strategic processing behaviors come to the forefront.

In previous research by the author (Kucer, 2008, 2009b) using a fourth grade literary narrative text with proficient fourth grade readers, speed, although a factor in predicting comprehension, was part of a complex matrix of various processing behaviors, such as the correction of meaning disrupting miscues and the use of context for predicting what was written. The number of miscues in and of themselves was unrelated to strong or weak retellings. Adding to this complexity was the relationship between clauses as finally read and the retelling of those clauses. Clauses containing uncorrected reader miscues that maintain the meaning of the author were significantly more likely to be recalled than clauses with no miscues. For example, the meaning of the clause, We're not at all alike, was more likely to recalled when read as, We're not alike than when read with no miscues. Or, Other people make a big thing of it was more likely recalled when read as, Other people make a big thing about it, than when read with no miscues. Such meaning maintaining miscues actually appeared to enhance comprehension, or at least recall. Miscues of this type appear to represent a "translation" of the surface structure into a form more familiar to the reader, yet still maintaining the deep structure of the clause. In these cases, although there was not accuracy in terms of reading the words correctly, there was accuracy in terms of correctly reading the meanings.

This relationship between uncorrected meaning maintaining issues and recall was not found to be the case, however, with expository scientific discourse (Kucer, 2011). Also using fourth graders and a fourth grade text, clauses read with uncorrected meaning maintaining miscues were no more likely to be recalled than clauses read with no miscues. This difference between the two discourses may be due to the significant role that background knowledge has been found to have on both reading processing as well as comprehension (Pearson, 2009). The literary text was about a missing library book and reflected experiences that the students were able to understand and may have actually experienced. In contrast, the scientific exposition addressed the impact of the forces of nature - wind, fire, water, temperature — on rock formation, scientific concepts unfamiliar to the students.

The differences may also be due to the academic nature of the two texts themselves. It is now recognized that reading is not a unitary, monolithic process that operates in identical ways across texts and contexts. Rather, texts in different disciplines may require different types or profiles of processing, depending on the reader, the purpose, and the content being encountered (Gavelek \& Bresnahan, 2009; Kucer, 2009b, 2011; New London Group, 1996; Shanahan, 2009). This is not to say that common cognitive processes are not used across text types and text disciplines. Clearly, readers predict and integrate meanings, monitor and evaluate the ideas being constructed, and draw upon background experiences regardless of the text being processed. However, the 
manner and the extent to which various processes are utilized, as well as the interaction among them, may differ across the disciplines.

The internal workings of academic texts are thought to be a significant factor in how such texts are ultimately processed. Some academic discourses are densely written with numerous facts, figures, and concepts packed into the sentence. This density is expressed in what is known as lexical density. Lexical density is the percent of content words (i.e., nouns, verbs, adjectives) in a text. It is these words that carry the bulk of the information in any text, in contrast to function words (i.e., prepositions, determiners, conjunctions, pronouns). Rather than relying on general world knowledge, these concepts, expressed through content words, require specialized ways of knowing, thinking, and being within the relevant discipline. In general, science texts have been found to reflect such characteristics, packing far more information into the clause than other kinds of discourse, spoken or written (Fang, 2004; Gee, 2004, 2012; Shanahan, 2009). This intertwining of new language structures and new concepts places new linguistic and cognitive demands on students, which can be overwhelming without instructional support and mediation (Baumann \& Graves, 2010; Carrasquillo, Kucer, \& Abrams, 2004; Cook, Borrego, Garza, \& Kloock, 2010; Greenleaf, Jimenez, \& Roller, 2002).

It is important to keep in mind that although academic forms differ from vernacular forms, not all academic forms are alike. Rather, different disciplinary texts represent different communities of practice and so too do their texts and discourses (Shanahan, 2009; Wilson, 2011). There is ample evidence, for example, that many elementary students reach the fourth grade highly proficient in reading narrative, fictional texts. However, these effective and efficient processing behaviors may not be evident when texts in such disciplines as science and mathematics are read. The so called "fourth grade slump"-lowered standardized reading scores in fourth grade-reflects this phenomenon (Allington, 2011). In fourth grade, the use of disciplinary expository texts becomes more common in the classroom and on reading achievement tests.

The study addresses some of the gaps in the research literature by using a literary narrative and scientific expository text with the same students. First, the relationship between processing behaviors and comprehension within each disciplinary text is examined. Secondly, processing behaviors and comprehension between the texts are compared and contrasted. Finally, reading behaviors beyond speed and accuracy, and comprehension on a local and global level, are included in the examination of the intersections among processing behaviors, academic discourses, and comprehension.

\section{Participants}

\section{Method}

Eighteen fourth graders - 10 females and eight males - from the same classroom participated in the study. Students attended a middle class school in the Pacific Northwest and the majority had college-educated parents. European American and monolingual in English, the students were deemed as proficient readers by district test scores as well as by their teacher. Based on the Qualitative Reading Inventory (QRI), the assessment used by the school district to evaluate reading progress, students were reading on the 4.39 grade level, with a range from $4.0-5.0$. The teacher indicated that the students were 
"typical" of fourth graders who were reading on grade level and had no basic processing problems. Proficient readers were used because they are said to have developed the fluency required for successful comprehension (e.g., Rasinski et al., 2011; Stahl \& Heubach, 2005).

\section{Materials}

With assistance from the classroom teacher, two books, one fictional narrative and one scientific expository, were selected from the Benchmark Assessment System 2 (Fountas \& Pinnell, 2008b). Although Benchmark 2 is widely known and used assessment system for grades 3 through 8, it was not employed in the school district in which the school was located, nor had the students encountered the texts in their fourth grade classroom. Each grade level of the System contains multiple pairs of literary narrative and expository-usually scientific and social science in nature-stand alone texts that can be used to evaluate student reading ability. The paired texts reflect the same readability characteristics and "have been matched so that if a student can read one genre, [s/]he should be able to read the other at the same level" (Fountas \& Pinnell, 2008, p. 6). The expository texts in the Assessment System, however, are intentionally shorter than the narratives, due to the increased processing demands that expository language and content typically place on readers (Baumann \& Graves, 2010; Gee, 2004; Shanahan, 2004b). A scientific text was selected because much of the focus of academic literacy has tended to focus on science. A literary narrative was used as the contrasting discourse because students typically have far more experiences and a higher comfort level with stories.

The literary narrative text, Could be Worse (Fear, 2008) and the scientific expository text, Amazing Animal Adaptations (Longo, 2008), were both on the late fourth grade readability level. The teacher thought the students would be able to process and comprehend the texts, yet still make miscues in their oral reading. Table 1 represents a linguistic analysis of the two texts. The narrative, Could Be Worse, was the longer of the two readings, consisting of 60 sentences, 100 clauses, and 593 words. Sentences, on average, contained 9.88 words and 1.65 clauses. Clauses contained 5.99 words on average. The text was accompanied by a single illustration. There is a mixture of dialogue between the Dad and his son, as well as between the son and the produce manager, Mr. Cardozo. Structurally, Could be Worse (Fear, 2008) reflected a typical story narrative frequently experienced by the students. There was an initiating event that caused a response by the main character. The character then attempted to reach his goal and when obtained, there was a consequence, followed by a reaction. 
Table 1

Linguistic Analysis of "Could Be Worse" and "Amazing Animal Adaptations"

\begin{tabular}{ccc}
\hline Text Feature & Could Be Worse & $\begin{array}{c}\text { Amazing Animal } \\
\text { Adaptations }\end{array}$ \\
\hline Pages & & \\
Sentences & 4 & 4 \\
Words per Sentence & 60 & 31 \\
Clauses & 9.88 & 15 \\
Words per Clause & 100 & 59 \\
Clauses per Sentence & 5.99 & 7.88 \\
Words & 1.65 & 1.9 \\
Text Structure & 593 & 465 \\
& Initiating event, response, & Introduction, three \\
attempt, consequence, & subtopics, summary \\
Academic Language & reaction & Camouflage (3), \\
& Inconspicuous (1) & environment (5), predators \\
Pictures/Illustrations & & (3), adaptation (4) \\
Subheadings & 1 & 3 \\
Use of dashes & 0 & 5 \\
Readability Level & 3 & 2 \\
& Late fourth grade & Late fourth grade
\end{tabular}

With the assistance of the classroom teacher, academic linguistic features that would have probably been new to the students were identified. The use of dashes three times, (e.g., I had an unauthorized stop to make on the way to school-one of those secrets I mentioned earlier), was a linguistic convention not found in the classroom texts used by the students. Additionally, there was a single academic word, inconspicuous, used once that was most likely unfamiliar as well.

In contrast, Amazing Animal Adaptations (Longo, 2008), the expository text, was 31 sentences in length, with 59 clauses and 465 words. As is common in many expository texts with academic language (e.g., Baumann \& Graves, 2010; Gee, 2004ab; Kucer 2009a, 2011; Shanahan, 2009), the sentences were linguistically and conceptually denser than those in the narrative. On average, sentences contained 15 words and 1.9 clauses. Clauses were 7.88 words in length. Amazing Animal Adaptations reflected an expository structure that introduced the issue, explored three examples of the issue, and then ended with a summary. Each example was accompanied by a subheading as well as a photograph. The photograph illustrated the physical adaptations addressed and was accompanied by a sentence noting the adaptations. Two of the three photographs were at the top of its own page. A third photograph was in the middle of the third page between two paragraphs. In the glossary of the book, three disciplinary words are identified and defined: camouflage, environment, and predators. Camouflage appears three times in the 
text, whereas environment appears five times and predators three times. Adaptation, the fourth academic term, is used four times. The use of dashes occurs twice.

In terms of content, Could Be Worse (Fear, 2008) is a short story about the life of a boy who is homeless and living in a van with his unemployed Dad. The boy works at a produce market to earn extra money and learns that the owner of the market is looking for a full-time produce manager. The boy puts a flyer advertising the job on their van; his Dad reads the flyer and gets the job. There is a picture illustrating the boy on his bicycle with his school sack lunch. This picture is also on the cover of the book, where the Dad and the van are included as well.

There were no homeless children in the class, but the financial crisis in the United States at the time of data collection had impacted the employment status of a number of parents throughout the school. The teacher indicated that the crisis had been discussed in general terms with the class during the year. Although not personally experiencing homelessness themselves, the idea was something that the students would have been able to comprehend.

Conceptually, as shown in Table 2, there are 14 main ideas or events in Could Be Worse (Fear, 2008). As previously noted, the organizational pattern was a familiar one to the student. However, the manner in which one particular idea was used to frame the beginning and ending of the text - and its use as the story's title — was probably a novel literary feature to the students. The story opens with a joke about how everything was going wrong for an unidentified man. The man comments that it could be worse; at least it is not raining. Then it starts to rain. The end of the story returns to the joke; the Dad comments that things could be worse. However, in this case there was no rain.

Table 2

Content Analysis of "Could be Worse" and "Amazing Animal Adaptations"

\section{Could Be Worse}

Joke about how everything went wrong. It could be worse; it could be raining. It starts to rain.

Living in a van.

Dad lost job, had no money,

Dad and boy lie and keep secrets.

Every Tuesday morning I earned a couple of bucks unloading produce.

I used the money for school supplies that I couldn't bear to ask my Dad to buy.
Amazing Animal Adaptations

\section{Deep in the Rain Forest}

These animals are able to survive through adaptations - ways animals look or behave that allow them to survive.

\section{The Jaguar}

The jaguar's tan and black-spotted coat blends in with its surroundings.

Its camouflage allows the jaguar to sneak up on its prey.

Jaguars are not picky eaters - they eat animals, both large and small.

Jaguars have large heads and powerful 
"Mr. Cardozo, any chance you could hire me permanently?"

"I really need a full-time produce manager."

I hand-lettered a flyer: HELP WANTED, PRODUCE MANAGER.

I spotted our van, slipped the flyer under the windshield wiper.

"You're looking at the new produce manager of Cardozo's Market," he said.

"Mr. Cardozo wondered how I knew about the job."

I'm proud of you for taking the initiative."

"It's not going to make us millionaires," said Dad. "But it could be worse." jaws that allow them to be fearsome hunters.

They are skilled swimmers, able to snatch fish, turtles, and small alligators.

The Giant Anteater

Its appearance is an example of how animals adapt to their environments.

With its huge claws, the anteater can rip into ants' nests.

Its long, pointy snout lets it poke its head into holes.

Using its long tongue, the anteater slurps up ants effortlessly.

\section{The Red-Eyed Tree Frog}

The red-eyed tree frog uses its sticky toe pads to cling to the underside of wet leaves.

The toe pads are like suction cups.

Its bright green skin blends in with the leaves so that enemies can not find it as it sleeps during the day.

When a predator disturbs a dozing frog, the frog's eyes fly open. The predator is surprised and dashes off.

\section{Summary}

All living things adapt to their environments.

Also shown in Table 2 are the 13 main ideas from Amazing Animal Adaptations (Longo, 2008). The text addresses how various physical and behavioral characteristics of animals represent an adaptation to their environment. The three main animals - jaguars, anteaters, and red-eyed tree frogs - are introduced as part of the rainforest. The concept of adaptation is then defined and concludes this first section. Following a bolded summary subsection, the text concludes with the definition of adaptation repeated. The students had some general knowledge of jaguars or jaguar-like animals (e.g., cougars, panthers) and frogs - anteaters seemed to be a novel animal to many of them. In discussions with the classroom teacher, it was thought that the idea of animals adjusting to their environment through changes in behavior or physical features was probably a new concept. The author of this particular text used framing as well. Adaptation was 
defined in the opening paragraph, restated in the final paragraph, and was also used as part of the text's title.

\section{Procedures}

Data collection. Oral readings and retellings served as primary data sources for this research. In addition, Qualitative Reading Inventory (QRI) reading levels and DIBEL Oral Reading Fluency (ORF) scores (words read correctly per minute) were collected from the classroom teacher.

Reading and retelling data were collected over a two week period, with one text being read each week. In the first week, nine students read Could be Worse (Fear, 2008) and the other nine read Animal Adaptations (Longo, 2008). The following week, the second text was read. Before reading, students were informed that they would be reading a text aloud, were to read for meaning or understanding, and would be asked to retell all that they could remember after finishing the reading without looking back to the text. No assistance would be provided when unknown words or ideas were encountered. Rather, students were told to do the best they could and to continue reading.

Following the instructions, the text was orally read, followed by a retelling and probes by the researcher. Probes were based on what the students had retold. Requests for elaborations and clarifications, as well as gaps in the retellings reflecting the main ideas represented in Table 2, were explored. Care was taken, however, not to introduce information the readers had not recalled. All readings, retellings, and probes were audiotaped. On average, each data collection session lasted approximately fifteen minutes.

Data analysis. Miscue analysis was the procedure used to capture the processing behaviors of the students (Davenport, 2002; Goodman, Watson, \& Burke, 2005; Wilde, 2000). Miscue analysis evaluates the degree to which readers utilize the various systems of language (e.g., graphophonemics, syntax, semantics), when interacting with written discourse. Through miscue analysis, all miscues (i.e., deviations from what was written), are marked. Markings include substitutions, omissions, insertions, pauses, corrections, attempts to correct, abandonment of correct responses, and repetitions. The goal of the marking is to capture the reader's processing of the discourse as fully as possible. In total, students generated 1,677 miscues across the reading of 2,862 clauses.

Typically, each sentence as finally read is then evaluated for its syntactic and semantic acceptability, as well as the degree to which the author's meaning has been maintained, changed, or disrupted. In this study, however, the clause was used as the unit of analysis because there is some research to suggest that it is the basic linguistic unit for processing (Gee, 2005, 2008; Hayes \& Nash, 1996). Following Gee (1999), a clause is defined as "any verb and the elements that 'cluster' with it..." (p. 99). For example, the second sentence in Could be Worse (Fear, 2008) contains three clauses, indicated by /: First he oversleeps / then, hustling out the door / he stubs his toe badly. In Amazing Animal Adaptations (Longo, 2008), the first sentence contains two clauses: Deep in the rain forest, after the sun has set / a sleek jaguar creeps along the forest floor. Because many of the sentences in the texts contained multiple verbs and therefore multiple clauses 
(1.65 clauses per sentence in Could be Worse; 1.9 clauses per sentence in Amazing Animal Adaptations), the use of the clause also allowed for a more discrete analysis of both processing and retelling behaviors.

Audiotaped readings for the two texts were reviewed and all miscues marked on a typed copy of the texts. On the typed copy, the sentences in the texts had been segmented into clauses and consecutively numbered. Each recorded reading was initially listened to and miscues marked by one researcher and then checked by a second. Differences between researchers were resolved during regular data analysis meetings, resulting in $100 \%$ agreement among the researchers. This procedure was replicated for all other nonstatistical data analysis procedures as well.

Each clause was then judged for semantics (acceptable or unacceptable) and author's meaning (maintenance, change, or disruption) as finally read. In order for a clause to be judged as semantically acceptable, it had to be grammatical and meaningful in and of itself, regardless of whether it maintained the original meaning of the author. For example, as illustrated in Table 3, the narrative text clause, make it easier for each other, was read as, make it easier for us, and judged as semantically acceptable. Similarly, the expository clause, Its long, pointy snout lets it poke its head into holes, was judged as semantically acceptable when read as, Its long, pointy snout lets it poke its head into the holes. In contrast, An opportunity to sleep in a bed, read as An operation to sleep in bed, was semantically unacceptable, as was The frog was huge, bulging red eyes. Clauses with no miscues or with corrected miscues were automatically judged as being semantically acceptable.

Table 3

Miscue Coding Samples

\begin{tabular}{ccc}
\hline Text & Reader & Coding \\
\hline
\end{tabular}

make it easier for each other make it easier for us

Semantically acceptable

Author meaning maintenance

Its long, pointy snout lets it Its long, pointy snout lets it poke its head into holes. poke its head into the holes

Its long, pointy snout lets it poke its head into holes.

"Already ate," he answered, just as casually.

The anteater is one of the
Its long, pointy snout lets it poke its head into the holes.
"Already late," he answered just as casually.

The anteater is one of the
Semantically acceptable

Author meaning maintenance

Semantically acceptable Author meaning Maintenance

Semantically acceptable Author meaning change

Semantically acceptable 
oddest-looking beasts in the animal world.

But what if a predator does find

"An opportunity to sleep in a bed"

Dad looked professional in his dress shirt, tie, and pressed

This frog has huge, bulging, red eyes

and a giant anteater arches home oddest-looking beasts in the world.

But if the predator doesn't find

"An operation to sleep in bed"

Dad looked professional in his dress shirt, tie, he pressed

The frog was huge, bulging, red eyes

And a giant antler marches home
Author meaning change.

Semantically acceptable Author meaning change

Semantically unacceptable Author meaning disruption

Semantically unacceptable Author meaning disruption

Semantically unacceptable Author meaning disruption

Semantically unacceptable Author meaning change

Author's meaning evaluated the degree to which the author's original ideas were maintained, changed, or disrupted. Again, as indicated in Table 3, the text clause, make it easier for each other, read as, make it easier for us, was coded as maintaining author meaning. Clauses were coded as meaning change when the intent of the author was altered, such as in the expository clause, But what if a predator does find, being read as, But if the predator doesn't find. Finally, clauses were classified as meaning disrupting when they made no sense as finally read. An operation to sleep in bed read for An opportunity to sleep in a bed was not meaningful within the context of the story. Clauses with no miscues or with corrected miscues were automatically judged as maintaining author meaning.

Finally, the number of words read per minute (WPM), number of miscues per hundred words, and total number of corrected miscues were calculated.

Reader comprehension was evaluated through an analysis of the retellings on a local (clause) and global (main idea) level. For the local level analysis, the retellings were segmented into clauses and numbered. In total, students generated 725 retold clauses across the reading of 2,862 clauses. Each clause in the retelling was then matched, when possible, with an equivalent clause in the text. In matches, the retold clause maintained the meaning of a clause within the text, although synonymous language might have been substituted for the original language. For example, as illustrated in Table 4, the retold narrative clause, Then he woke up late, was matched with the text clause, First he oversleeps. Or, the recalled expository clause, They are also skilled swimmers, matched with the retold clause, Jaguars are good swimmers. On occasion, the meanings of a single recalled clause were located in two text clauses, or, conversely, the meanings of a single text clause were located in two recalled clauses. Such clauses were coded as a match since the meaning in the retelling had fully captured the meaning represented in the text, although in two separate clauses. 
Table 4

Clause Retelling Coding Samples

\begin{tabular}{|c|c|c|}
\hline Text & Retelling & Coding \\
\hline First he oversleeps & Then he woke up late & Match \\
\hline locked out & $\begin{array}{l}\text { Then I think he lock, he } \\
\text { locked the door behind him } \\
\text { so then he couldn't get back } \\
\text { in }\end{array}$ & Match \\
\hline $\begin{array}{l}\text { They are also skilled } \\
\text { swimmers }\end{array}$ & Jaguars are good swimmers & Match \\
\hline \multicolumn{3}{|c|}{ its eyes pop open } \\
\hline $\begin{array}{l}\text { As well as a micro- } \\
\text { the global level. In most c } \\
\text { bigger ideas rather than } \\
\text { illustrated in Table 2, Cou } \\
\text { Amazing Animal Adaptatio } \\
\text { critical to an understanding } \\
\text { possible, with main ideas i } \\
\text { synthesis of ideas in the tex } \\
\text { the text and the retelling, } \\
\text { idea in the literary text, } E \\
\text { produce, was retold as, } \\
\text { working at the Cardozo's } \\
\text { The jaguar can blend in w } \\
\text { tan and black-spotted coat }\end{array}$ & $\begin{array}{l}\text { alysis on the clause level, rete } \\
\text { texts, readers are more likely } \\
\text { the recall of particulars. } \\
\text { Be Worse (Fear, 2008) cont } \\
\text { s (Longo, 2008) contained } 13 \text {. } \\
\text { f the topics addressed. Main id } \\
\text { the retellings. As shown in Ta } \\
\text { Unlike clauses which could fr } \\
\text { ajor ideas might be developed } \\
\text { ry Tuesday morning I earned } \\
\text { thefore school he earned a } \\
\text { oduce place. Or, the retold ma } \\
\text { the tree trunks, was addresse } \\
\text { ends in with its surroundings. }\end{array}$ & $\begin{array}{l}\text { e also evaluated on } \\
\text { n remembering the } \\
\text { sly discussed and } \\
\text { nain ideas whereas } \\
\text { eas were judged as } \\
\text { hen matched, when } \\
\text { in ideas represent a } \\
\text { e matched between } \\
\text { clauses. The main } \\
\text { of bucks unloading } \\
\text { 's because he was } \\
\text { the scientific text, } \\
x \text { as, The jaguar's }\end{array}$ \\
\hline
\end{tabular}

Table 5

Main Ideas Retelling Coding Samples

\begin{tabular}{|c|c|c|}
\hline Main Idea & Retelling & Coding \\
\hline $\begin{array}{l}\text { Every Tuesday morning I earned } \\
\text { a couple of bucks unloading } \\
\text { produce }\end{array}$ & $\begin{array}{l}\text { But before school he earned a } \\
\text { few dollars because he was } \\
\text { working at the Cardozo's } \\
\text { produce place }\end{array}$ & Match \\
\hline
\end{tabular}


I used the money for school supplies that I couldn't bear to ask my Dad to buy.

The jaguar's tan and blackspotted coat blends in with its surroundings.

With its huge claws, the anteater can rip into ant's nests.
So he could earn some money for school supplies; because they barely had any money

The jaguar can blend in with the tree trunks.

and they have sharp claws that can rip open the ant's houses
Match

Match

Match

\section{Results}

Bivariate correlations were conducted to explore the relationships among the following behavior variables and clause recall: QRI reading level, DIBELS ORF score, WPM, miscues, corrected miscues, semantically acceptable and unacceptable clauses, and author meaning maintaining, changing, and disrupting. For the recall of main ideas, the same variables were examined, with the addition of recalled clauses. Within text relationships are first discussed, followed by a discussion of between text relationships.

\section{Within Text Relationships}

Tables 6 and 7 show the means and standard deviations for the variables examined within the literary and scientific texts. For the literary text, two variables were significantly related to clause recall: the number of author meaning maintaining clauses ( $M=65.89, S D=21.89), r=.48, p=.05$ was positively related to the retelling of clauses whereas the number of author meaning changing clauses $(M=3$. $S D=3.50), r=-.50, p$ $=.05$ was negatively related to clause retelling. Once again, the relationship of clause recall that was read with no miscues and read with uncorrected author meaning maintaining miscues was examined. No significant difference was found between uncorrected meaning maintaining miscues $(M=12.78 \%, S D=7.61 \%)$ and clauses read with no miscues $(M=15.04 \%, S D=7.03 \%), t=.92, \alpha=.36$. Additionally, two variables were significantly related to the retelling of main ideas, author meaning maintaining clauses $(M=65.98, S D=21.89), r=.47, p=.05)$ and matching clause retold $(M=14.33$, $S D=5.86) r=.83, p=.00)$.

Table 6

Literary Text Means and Standard Deviations

\begin{tabular}{ccc}
\hline Variable & $\mathrm{M}$ & $\mathrm{SD}$ \\
\hline 1. QRI & 4.39 & .61 \\
2. ORF & 144.94 & 40.99 \\
3. WPM & 119.22 & 29.07 \\
4. Number of miscues & 49.83 & 40.76 \\
5. Number of corrected miscues & 17.67 & 11.58
\end{tabular}


6. Number of semantically acceptable clauses

88.39

7.98

7. Number of semantically unacceptable clauses

$11.61 \quad 7.98$

8. Number of author meaning maintaining clauses *

$85.28 \quad 10.88$

9. Number of author meaning changing clauses *

$3.11 \quad 3.50$

10. Number of author meaning disrupting clauses

$11.61 \quad 7.98$

11. Number of matching clauses retold $* *$

$14.33 \quad 5.86$

12. Number of main ideas retold

6.61

2.40

Note. ${ }^{*} p<.05 . * * p<.01$.

Table 7

Scientific Text Means and Standard Deviations

\begin{tabular}{|c|c|c|}
\hline Variable & M & SD \\
\hline 1. QRI & 4.39 & .61 \\
\hline 2. ORF & 144.94 & 41.00 \\
\hline 3. WPM & 118.80 & 21.48 \\
\hline 4. Number of miscues & 43.33 & 40.31 \\
\hline 5. Number of corrected miscues & 13.00 & 6.64 \\
\hline $\begin{array}{l}\text { 6. Number of semantically } \\
\text { acceptable clauses }\end{array}$ & 47.78 & 8.56 \\
\hline $\begin{array}{l}\text { 7. Number of semantically } \\
\text { unacceptable clauses }\end{array}$ & 10.44 & 8.32 \\
\hline $\begin{array}{l}\text { 8. Number of author meaning } \\
\text { maintaining clauses }\end{array}$ & 46.50 & 8.47 \\
\hline $\begin{array}{l}\text { 9. Number of author meaning } \\
\text { changing clauses }\end{array}$ & 1.56 & 1.89 \\
\hline $\begin{array}{l}\text { 10. Number of author meaning } \\
\text { disrupting clauses }\end{array}$ & 10.17 & 7.72 \\
\hline $\begin{array}{l}\text { 11. Number of matching clauses } \\
\text { retold } *\end{array}$ & 13.00 & 5.40 \\
\hline 12. Number of main ideas retold & 4.5 & 2.18 \\
\hline
\end{tabular}

Note. $* p<.01$.

No factors were found to be significantly related to clause retelling on the 
scientific text. However, there was a significant difference between clauses read with no miscues and those read with uncorrected meaning maintaining miscues $(t=2.17, \alpha=$ $.04)$. Clauses with no miscues $(M=18.15 \%, S D=7.42 \%)$ were significantly less likely to be recalled than those read with meaning maintaining miscues $(M=26.56 \%, S D=$ $14.69 \%$ ). Accuracy in terms of maintaining meaning was more significant than accuracy in terms of word identification. Finally, one variable, matching clauses retold, was significantly related to the retelling of main ideas $(M=13.00, S D=5.40), r=.73, p=.00$.

\section{Between Text Relationships}

The one behavior that was related to the recall of main ideas on both texts was the recall of clause level ideas. These clauses served to support the development and recall of main points of the authors, regardless of the discipline. Additionally, for the literary text, clause processing that maintained the author's meaning regardless of miscues also supported the development of main ideas.

In contrast, processing behaviors and clause recall varied between the two texts. For the literary text, clauses that maintained author meaning with or without miscues were significantly more likely to be recalled. However, processing that changed the meaning of the clause, although still meaningful in and of itself, were less likely to be called. For the scientific text, processing behaviors were not found to be as directly related to comprehension, with one exception. Clauses containing miscues that maintained author meaning were significantly more likely to be recalled than clauses with no miscues.

\section{Discussion}

Given the current educational climate in terms of literacy instruction, it might useful to begin with those factors that were unrelated to comprehension at either the clause or main ideas level across and within the literary and scientific texts. Reading ability levels as determined by the QRI, QRF abilities as determined by DIBELS, WPM, and number of miscues (accuracy) did not significantly impact reader comprehension. Interestingly, several of these factors-ORF, WPM, accuracy-are related to the construct of fluency.

This lack of significance builds upon previous research using literary narratives on the link between rate and comprehension for more accomplished readers (Allington \& McGill-Franzen, 2009; Paris et al., 2005), but importantly extends it to scientific expository discourse as well. It also supports existing research (e.g., Goodman, 2006) that DIBELS "at best is a measure of who reads quickly without regard to whether the reader comprehends what is read" (Pressley, Hilden, \& Shankland, 2006, p. 2). This lack of a significant relationship between rate and comprehension may be an example of the diminishing impact of constrained skills as readers develop increased proficiency (Paris, et al., 2005; Paris \& Hamilton, 2009).

Flurkey (2008) has also challenged the notion that speed and accuracy are characteristics of proficient readers. He reconceptualizes fluency as flow. Like a stream or river, which varies in its flow based on the terrain through which it travels, proficient readers vary their speed based on the terrain (e.g., content, language use, text structure), of the text. In his research with elementary school children, readers were found to their 
vary rate throughout the text, based on the linguistic and conceptual demands of the sentence or paragraph. In fact, proficient readers actually demonstrated even greater variability in reading rates than those less proficient. In essence, processing speeds were based on the needs of the reader.

A powerful factor that was positively associated with the recall of clauses and main ideas across both texts is the readers' ability to maintain the meaning of what is being processed. Clauses that were read in a way that made sense and that did not disrupt the author's meaning, regardless of the existence of miscues, not only were more likely to be recalled, but were associated with main idea recall as well. Instructionally, a focus on helping readers develop strategies to maintain the author's meaning, rather than on accuracy and speed, might better promote comprehension development in elementary students. Demonstrating the use of context clues that precede and follow unknown words to determine their meaning, as well as explicitly pointing out the various ways authors define particular concepts within their texts, can begin to address this issue (e.g., Lapp, Fisher, \& Grant, 2008; Stahl \& Nagy, 2006). Such instruction would also need to include helping students to understand the linguistic and conceptual nature of sentences within expository discourses, and how they differ from more well-known narrative structures. Contrastive analysis of sentences in various types of academic texts is one fruitful way this might be accomplished (e.g., Adger, Wolfram, \& Christian, 2007; Wheeler \& Swords, 2004). Finally, on a larger structural level, students can also be taught the various text organizational patterns that are reflected in different types of academic discourse, using the well known narrative structure as a contrastive base (Kucer \& Silva, 2013).

Of particular interest are the differences in processing and comprehension between the literary and scientific texts. For the literary, maintaining the meaning of the clause and fewer author meaning changing miscues were the only factors related to clause recall. No processing factors were found to be related to clause recall on the scientific text. The current research did find, however, that uncorrected meaning maintaining miscues were more likely to be recalled than clauses with no miscues. That is, clauses containing uncorrected miscues that did not change or disrupt the author's meaning appeared to enhance the possibility of this meaning being recalled. A focus on helping students to monitor and correct miscues that disrupt or change meaning, and not on those miscues that maintain meaning, would be a better use of instructional time.

Given the limited number of processing behaviors associated with the comprehension of the scientific expository text, it may be the case that a lack of reader background knowledge actually 'trumped' processing variables and abilities. The significance of prior knowledge on comprehension in general, and on academic discourse in particular, is well documented (e.g., Baumann, 2009; Gee, 2004; Kucer, 2011; Paris et al., 2005; Shanahan, 2009). Such specialized knowledge may be at play in this research as well. For example, students miscued on the word adaptation-reading it as adoptation - and appeared confused about the concept upon which the entire text was based.

A previously mentioned, the classroom teacher had indicated that the students had most likely not previously encountered in their science classes the idea of animals physically adapting to their environment. No amount of efficient and effective processing 
could have made up for this lack of prior knowledge. However, when readers did have the cognitive resources to maintain meaning even though they miscued, these meanings appeared to be more salient and were more likely to be remembered. In fact, the meanings of clauses with meaning maintaining miscues were even more likely to be recalled than clauses containing no miscues. In such cases, readers appeared to be using their preferred language rather than the authors, yet still maintained meaning. Building student background knowledge as it relates to the content of expository texts might be one avenue to provide students with the cognitive resources necessary for successful processing. Thematic curricula have been demonstrated as one way such background knowledge might be developed (Kucer \& Silva, 2013). In such curricula, both language and concepts are 'recycled' through numerous lessons and activities. Such recycling affords students ample opportunities to develop linguistic and conceptual knowledge related to the theme topic.

\section{Conclusions, Limitations, and Future Research}

This research begins to tease out those variables that do and do not impact student comprehension on both narrative and expository texts. Moving beyond speed and accuracy, which were not found to be relevant for either type of discourse, the maintenance of meaning while reading as well as the availability of relevant background knowledge were significant factors in the readers' ability to comprehend the texts. This impact of background knowledge on both processing and comprehension is especially relevant for expository discourse. These texts frequently reflect specialized ways with words and concepts that are beyond the experiences of many readers.

Although the students in this study read 2,862 clauses across two different disciplinary texts, generated 1,677 miscues, and retold 725 clauses, only 18 fourth graders from a single classroom were involved. This limitation requires that future research involve far larger numbers of readers, as well as readers at different grade levels. Students should represent a variety of cultural and linguistic backgrounds, as well as socioeconomic statuses. Furthermore, the examination of processing factors and comprehension across other disciplinary fields, such as mathematics and social studies, would further expand our understanding of academic literacies. Texts would represent disciplinary content with which students have high and low degrees of familiarity and specialized background knowledge. As demonstrated in this research, once again background knowledge was found to play a significant role in both text processing and text comprehension.

\section{References}

Adger, C., Wolfram, W., \& Christian, D. (2007). Dialects in schools and communities (2nd ed.). Mahwah, NJ: Erlbaum.

Allington, R. (2011). What really matters for struggling readers: Designing research based programs (3rd ed.). New York, NY: Pearson.

Allington, R., \& McGill-Franzen, A. (2009). Comprehension difficulties among struggling readers. In S. Israel \& G. Duffy (Eds.), Handbook of research on reading comprehension (pp. 551-568). New York, NY: Routledge. 
Baumann, J. (2009). Vocabulary and reading comprehension: The nexus of meaning. In S. Israel \& G. Duffy (Eds.), Handbook of research on reading comprehension (pp. 323-346). New York, NY: Routledge.

Baumann, J., \& Graves, M. (2010). What is academic language? Journal of Adolescent and Adult Literacy, 54, 4-12.

Breznitz, Z. (2006). Fluency in reading: Synchronization of processes. Mahwah, NJ: Erlbaum.

Carrasquillo, A., Kucer, S. B., \& Abrams, R. (2004). Beyond the beginnings: Literacy interventions for upper elementary English language learners. Clevedon, UK: Multilingual Matters LTD.

Cavagnetto, A. (2010). Argument to foster scientific literacy: A review of argument interventions in K - 12 science contexts. Review of Educational Research, 80, 336-371.

Cook, D. L., Borrego, I., Garza, E., \& Kloock, C. (2010). Academic language/literacy strategies for adolescents: A how to" manual for educators. New York, NY: Routledge.

Davenport, M. R. (2002). Miscues not mistakes: Reading assessment in the classroom. Portsmouth, NH: Heinemann.

Dowhower, S. (1994). Repeated research revisited: Research into practice. Reading and Writing Quarterly, 10, 343-358.

Fang, Z. (2004). Scientific literacy: A systemic functional linguistics perspective. Scientific Education, 89, 335-347.

Fear, S. (2008). Could be worse. In I. Fountas \& G. Pinnell, Benchmark assessment system 2. Portsmouth, NH: Heinemann.

Flurkey, A. (2008). Reading flow. In A. Flurkey, E. Paulson, \& K. Goodman (Eds.), Scientific realism in studies of reading (pp. 267-304). New York, NY: LEA/Taylor \& Francis.

Fountas, I.,\& Pinnell, G. (2008). Benchmark assessment system 2. Portsmouth, NH: Heinemann.

Gavelek, J., \& Bresnahan, P. (2009). Ways of meaning making: Sociocultural perspectives on reading comprehension. In S. Israel \& G. Duffy (Eds.), Handbook of research on reading comprehension (pp. 140-176). New York, NY: Routledge.

Gee, J. (1999). An introduction to discourse analysis: Theory and method. New York, NY: Routledge.

Gee, J. (2004). Language in the science classroom: Academic social languages as the heart of school-based literacy. In S.W. Saul (Ed.), Crossing boarders in literacy and science education: Perspectives on theory and practice (pp. 13-32). Newark, DE: International Reading Association.

Gee, J. (2005). An introduction to discourse analysis: Theory and method (2nd ed.). New York, NY: Routledge.

Gee, J. (2008). An introduction to discourse analysis: Theory and method (3rd ed.) New York, NY: Routledge.

Gee, J. (2012). Social Linguistics and literacies: Ideology in discourses (4th ed.). New York, NY: Routledge. 
Good, R., \& Kaminski, R. (2005). Dynamic indicators of basic early literacy skills (6th ed.). Eugene, OR: Institute for the Development of Educational Achievement.

Goodman, K. (2006). The truth about DIBELS: What it is, what it does. Portsmouth, NH: Heinemann.

Goodman, Y., Watson, D., \& Burke, B. (2005). Reading miscue inventory: From evaluation to instruction (2nd ed.). Katonah, NY: Owens.

Greenleaf, C., Jimenez, R., \& Roller, C. (2002). Conversations: Reclaiming secondary reading interventions: From limited to rich conceptions, from narrow to broad conversations. Reading Research Quarterly, 37, 484-496.

Hayes, J., \& Nash, J. (1996). On the nature of planning. In C. Levy \& S. Randsdell (Eds.), The science of writing: Theories, methods, individual differences, and applications (pp. 29-55). Mahwah, NJ: Erlbaum.

Honig, S. (2010). A framework for supporting scientific language in primary grades. The Reading Teacher, 64, 23-32.

Hudson, R., Pullen, P., Lane, H., \& Torgesen, J. (2009). The complex nature of reading fluency: A multidimensional view. Reading and Writing Quarterly, 25, 4-32.

Kucer, S. B. (2008). Speed, accuracy, and comprehension in the reading of elementary students. Journal of Reading Education, 34, 33-38.

Kucer, S. B. (2009a). Dimensions of literacy: A conceptual base for teaching reading and writing in school settings (3rd ed.). New York, NY: Taylor and Francis/Routledge.

Kucer, S. B. (2009b). Examining the relationship between text processing and text comprehension in fourth grades readers. Reading Psychology, 30, 340-358.

Kucer, S. B. (2011). Processing expository discourse: What factors predict comprehension? Reading Psychology, 32, 567-583.

Kucer, S. B., \& Silva, C. (2013). Teaching the dimensions of literacy ( $2^{\text {nd }}$ ed.). New York, NY: Taylor and Francis/Routledge.

Kuhn, M., \& Stahl, S. (2004). Fluency: A review of developmental and remedial practices. In R. Ruddell \& N. Unrau (Eds.), Theoretical models and processes of reading (5th ed.) (pp. 412-453). Newark, DE: IRA.

Lapp, D., Fisher, D., \& Grant, M. (2008). "You can read this text-I'll show you how": Interactive comprehension instruction. Journal of Adolescent and Adult Literacy, 51, 372-383.

Longo, D.M. (2008). Amazing animal adaptations. In I. Fountas \& G. Pinnell (Eds.), Benchmark assessment system 2. Portsmouth, NH: Heinemann.

New London Group. (1996). A pedagogy of multiliteracies: Designing social futures. Harvard Educational Review, 66, 60-92.

NICHD. (2000). The report of the National Reading Panel: Teaching children to read. Washington, DC: National Institute of Health.

Paris, S., Carpenter, R., Paris, A., \& Hamilton, E. (2005). Spurious and genuine correlates of children's reading comprehension. In S. Paris \& S. Stahl (Eds.), Children's reading comprehension and assessment (pp. 131-160). Mahwah, NJ: Erlbaum.

Paris, S., \& Hamilton, E. (2009). The development of children's reading comprehension. In S. Israel \& G. Duffy (Eds.), Handbook of research on reading comprehension 
(pp. 32-53). NY: Routledge.

Pearson, P. D. (2009). The roots of reading comprehension instruction. In S. Israel \& G. Duffy (Eds.), Handbook of research on reading comprehension (pp. 3-31). New York, NY: Routledge.

Pressley, M., Hilden, K., \& Shankland, R. (2006). An evaluation of end-of-grade 3 Dynamic Indicators of Basic Early Literacy Skills (DIBELS): Speed reading without comprehension, predicting little. East Lansing: Literacy Achievement Research Center, Michigan State University.

Rasinski, T. (2006). A brief history of reading fluency. In S.J. Samuels \& A.E. Farstrup (Eds.), What research has to say about fluency instruction (pp. 4-23). Newark, De: International Reading Association.

Rasinski, T., Reutzel, D. R., Chard D., \& Linan-Thompson, S. (2011). Reading fluency. In M. Kamil, P. D. Pearson, E. Birr Moje, \& P. Afflerbach (Eds.), Handbook of reading research: Volume IV (pp. 286-319). New York, NY: Routledge.

Samuels, S. J. (2006). Toward a model of reading fluency. In S.J. Samuels \& A. Farstrup (Eds.), What research has to say about fluency instruction (pp. 24-46). Newark, DE: IRA.

Shanahan, C. (2004a). Better textbooks, better readers and writers. In Saul, E.W. (Ed.), Crossing boarders in literacy and science education: Perspectives on theory and practice (pp. 370-382). Newark, De: International Reading Association.

Shanahan, C. (2004b). Teaching science through literacy. In T. Jetton \& J. Dole (Eds.), Adolescent literacy research and practice (pp. 75-93). New York, NY: Guilford.

Shanahan, C. (2009). Disciplinary comprehension. In S. Israel \& G. Duffy (Eds.), Handbook of research on reading comprehension (pp. 240-322). New York, NY: Routledge.

Stahl, S., \& Heubach, K. (2005). Fluency-oriented reading instruction. Journal of Literacy Research, 37, 25-60.

Stahl, S., \& Nagy, W. (2006). Teaching concepts. In S. Stahl \& W. Nagy (Eds.), Teaching word meanings (pp. 77-96). Mahwah, NJ: Erlbaum.

Torgesen, J., \& Hudson, R. (2006). Reading fluency: Critical issues for struggling readers. In S.J. Samuels \& A. Farstrup (Eds.), What research has to say about fluency instruction (pp. 130-158). Newark, DE: IRA.

Walczyk, J., \& Giffith-Rose, D. (2007). How important is reading skill fluency for comprehension? The Reading Teacher, 60, 560-569.

Wheeler, R., \& Swords, R. (2004). Codeswitching: Tools of language and culture transform the dialectally diverse classroom. Language Arts, 81, 470-480.

Wilde, S. (2000). Miscue analysis made easy: Building on student strengths. Portsmouth, NH: Heinemann.

Wilson, A. (2011). A social semiotics framework for conceptualizing content area literacies. Journal of Adolescent and Adult Literacy, 54, 435-444. 


\section{Author Biography}

Stephen B. Kucer is a Professor of Language and Literacy Education in the Department of Teaching and Learning in the College of Education at Washington State University Vancouver. His scholarly interests focus on the nature of literacies, the relationship between how texts are processed and comprehended, and the impact of text structure and text content on comprehension. 